\title{
Physicochemical Characterization and Cyclodextrin Complexation of the Anticancer Drug Lapatinib
}

\author{
Gergő Tóth,, Ádám Jánoska, ${ }^{1}$ Gergely Völgyi, ${ }^{1}$ Zoltán-István Szabó, ${ }^{2}$ \\ Gábor Orgován, ${ }^{1}$ Arash Mirzahosseini, ${ }^{1}$ and Béla Noszál ${ }^{1}$ \\ ${ }^{1}$ Department of Pharmaceutical Chemistry, Semmelweis University, Högyes Endre U. 9, Budapest 1092, Hungary \\ ${ }^{2}$ Department of Drugs Industry and Pharmaceutical Management, University of Medicine and Pharmacy, \\ Gh. Marinescu 38, 540139 Târgu Mureş, Romania
}

Correspondence should be addressed to Arash Mirzahosseini; mirzahosseini.arash@pharma.semmelweis-univ.hu

Received 24 November 2016; Accepted 9 February 2017; Published 1 March 2017

Academic Editor: Jaime Villaverde

Copyright (C) 2017 Gergő Tóth et al. This is an open access article distributed under the Creative Commons Attribution License, which permits unrestricted use, distribution, and reproduction in any medium, provided the original work is properly cited.

\begin{abstract}
Lapatinib (LAP), the tyrosine kinase inhibitor drug with moderate bioavailability, was characterized in terms of physicochemical properties: acid-base characteristics, lipophilicity, and solubility. The highly lipophilic nature of the drug and its extremely low water solubility $\left(S_{0}=0.82 \mathrm{nM}\right)$ limit the development of a parenteral formulation. In order to enhance solubility and bioavailability, inclusion complex formation with cyclodextrins (CDs) is a promising method of choice. Therefore, LAP-CD interactions were also studied by a multianalytical approach. The stability constants of LAP with native cyclodextrins, determined by UV spectroscopy, identified the seven-membered $\beta$-CD as the most suitable host. Continuous variation method (Job's plot) by ${ }^{1} \mathrm{H}$ NMR showed a 1:1 stoichiometry for the complexes. The geometry of the complex was elucidated by 2D ROESY NMR measurements and molecular modeling, indicating that the partial molecular encapsulation includes the fluorophenyl ring of LAP. Phase-solubility studies with four CDs, $\beta$-CD, (2-hydroxypropyl)- $\beta$-cyclodextrin (HP- $\beta$-CD), randomly methylated- $\beta$ - (RAMEB-) cyclodextrin, and sulfobutylether- $\beta$-cyclodextrin $(\mathrm{SBE}-\beta-\mathrm{CD})$, show an $\mathrm{A}_{\mathrm{L}}$ type diagram and highly increased solubility via CD complexation. The results are especially promising with SBE- $\beta-\mathrm{CD}$, exerting more than 600 -fold gain in solubility. The equilibrium and structural information presented herein can offer the molecular basis for an improved drug formulation with enhanced bioavailability.
\end{abstract}

\section{Introduction}

Lapatinib (LAP) (Figure 1) is a potent and selective inhibitor of the epidermal growth factor receptor (EGFR) and human epidermal growth factor receptor 2 (HER2) [1].

The drug is marketed as its ditosylate salt, in form of a film-coated tablet (Tyverb/Tykerb ${ }^{\circledR}$ ). It is currently used in combination therapy with capecitabine or letrozole for the treatment of HER2-positive advanced or metastatic breast cancer $[2,3]$. The pharmacokinetic properties of LAP are not optimal. Its oral bioavailability is moderate at best, it has considerable interpatient variability [4], and it is significantly affected by food intake. Both low-fat and high-fat diets before LAP administration increased its systematic exposure $[4,5]$. Besides food intake, gastric $\mathrm{pH}$ also influences LAP bioavailability. Higher gastric $\mathrm{pH}$ reduces LAP absorption; therefore, concomitant use of proton-pump inhibitors (PPIs) can decrease its bioavailability [6]. The recommended dose of LAP is $1,250-1,500 \mathrm{mg}$ once daily, which means taking 5-6 tablets at once, reducing patient adherence to therapy. Increasing the bioavailability of LAP could reduce the dose. Thus, a novel formulation with high solubility and bioavailability is currently an unmet medical need.

Enhancement of solubility and the concomitant bioavailability can be achieved by various means, such as solid dispersion, size reduction, cosolvency, polymorphism, formation of water soluble prodrug, or complexes [7]. Cyclodextrin (CD) complexation is one of the most extensively investigated ways to improve drug solubility and bioavailability [8].

CDs are cyclic oligosaccharides comprising six, seven, or eight $\mathrm{D}$-glucose units $(\alpha-, \beta$-, and $\gamma$-CD, resp.) that have been recognized as pharmaceutical adjuvants for the past 20 years. CDs have a hydrophilic surface responsible for their water solubility and a hydrophobic, inner cavity, where lipophilic 


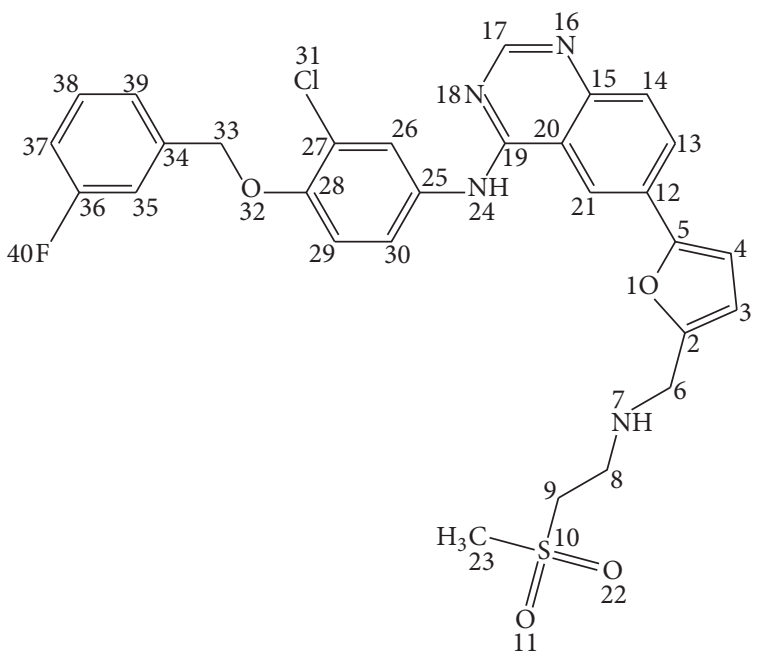

FIgURE 1: Chemical structure and numbering of LAP.

molecules with adequate dimensions can be accommodated forming a noncovalently bonded host-guest complex, conferring an increased aqueous solubility for the encapsulated molecule. Besides native CDs, several modified derivatives are also available, differing in nature, position of substituents, and average degree of substitution, in order to enhance the inclusion capacity and improve the physicochemical properties of the parent, native CDs $[9,10]$. Many advantages of inclusion complexation have been reported, such as increased solubility, enhanced bioavailability, improved stability, taste and odor masking, reduced volatility, and modified drug release [11].

So far only a few attempts have been reported to improve the bioavailability of LAP [12-14]. To the best of our knowledge, LAP-CD inclusion complex characterization has yet to be described, despite the fact that CD complexation has been proven to increase the solubility, bioavailability, and anticancer activity of other tyrosine kinase inhibitors erlotinib, gefitinib, imatinib, and so forth [15-19]; moreover, sulfobutylether- $\beta$-CD was used for solubilizing LAP in some earlier studies [20, 21].

Here we report the quantified biorelevant physicochemical properties of LAP. On the basis of the protonation constants, lipophilicity, and solubility parameters, we focus on the characterization and optimization of complex formation between various CDs and LAP. The information presented herein can be useful for the development of a new, improved LAP formulation. The methods used in this study include UV and NMR spectroscopy, electrospray ionization-mass spectrometry (ESI-MS), phase-solubility, and molecular modeling.

\section{Materials and Methods}

2.1. Materials. All CDs $(\alpha-\mathrm{CD}, \beta-\mathrm{CD}, \gamma-\mathrm{CD},(2$-hydroxypropyl)- $\beta$-CD (HP- $\beta$-CD), random methylated $\beta$ - (RAMEB-) $\mathrm{CD}$ and sulfobutylether- $\beta$-CD (SBE-CD)) were the products of Cyclolab R\&D Ltd., Hungary. Degree of substitution (DS) of HP- $\beta$-CD, RAMEB, and SBE-CD was $\sim 4.5, \sim 12$, and 6.5 , respectively. LAP was purchased from Eurasia's Ltd., India. Tris(hydroxymethyl)aminomethane (Tris), $\mathrm{H}_{3} \mathrm{PO}_{4}$, $\mathrm{KH}_{2} \mathrm{PO}_{4}, \mathrm{KOH}, \mathrm{NaOH}, \mathrm{HCl}$, and $\mathrm{KCl}$ were of analytical grade from commercial suppliers. $\mathrm{D}_{2} \mathrm{O}, \mathrm{DCl}$, dimethylsulfoxide (DMSO), hexadeuterated dimethylsulfoxide (DMSO- $d_{6}$ ), and $n$-octanol were obtained from Sigma-Aldrich, while $\mathrm{MeOH}$ was from Merck. Ultrapure, deionized water was prepared by a Milli-Q Direct 8 Millipore system.

2.2. Determination of Protonation Constant by UV-pH Titration. The $\log K$ value of LAP was determined by UV$\mathrm{pH}$ titration, using the D-PAS ${ }^{\mathrm{TM}}$ ultraviolet spectrophotometer attached to a GLpKa instrument (Sirius Analytical Instruments Ltd., Forest Row, UK). Multiwavelength UV absorbance of the sample solution was monitored throughout the titration using the fiber-optic probe in situ [22]. The UV$\mathrm{pH}$ titrations were carried out under nitrogen atmosphere at constant ionic strength $(I=0.15 \mathrm{M} \mathrm{KCl})$ and temperature $\left(t=25.0 \pm 0.5^{\circ} \mathrm{C}\right)$. Due to the very low solubility of LAP, the cosolvent method was used to determine its $\log K$ value. The cosolvent protonation constants ( $\log K^{\prime}$ values) were determined in six different $\mathrm{MeOH}$-water mixtures within 23$43 \%$ (w/w). A stock LAP solution of $7 \mathrm{mM}$ concentration was prepared in DMSO. In each experiment, $75 \mu \mathrm{L}$ of the stock solutions was transferred into sample vials containing $15 \mathrm{~mL}$ of $0.15 \mathrm{M} \mathrm{KCl}$ solution to achieve the required sample concentration. In each experiment, the acidity of the sample solution was adjusted using $0.5 \mathrm{M} \mathrm{HCl}$ to about $\mathrm{pH}^{*} 2.5$ and then titrated with $0.5 \mathrm{M} \mathrm{KOH}$ to about $\mathrm{pH}^{*}$ 9. Spectral data were recorded in the 200-700 $\mathrm{nm}$ region after each $\mathrm{pH}$ measurement. About $20 \mathrm{pH}$ readings and absorption spectra were collected from each titration. The $\log K^{\prime}$ values were calculated by RefinementPro ${ }^{\mathrm{TM}}$ software.

The measured $\log K^{\prime}$ values in $\mathrm{MeOH}$-water solutions were then extrapolated to aqueous condition (zero $\mathrm{MeOH}$ concentration) according to the Yasuda-Shedlovsky procedure [23]. The Yasuda-Shedlovsky extrapolation method is based on the linear relation between $\log K^{\prime}$ and the dielectric constant $(\varepsilon)$ of the cosolvent mixture:

$$
\log K^{\prime}+\log \left[\mathrm{H}_{2} \mathrm{O}\right]=\frac{a}{\varepsilon}+b
$$

where $\varepsilon$ is the dielectric constant, and $\log \left[\mathrm{H}_{2} \mathrm{O}\right]$ is the molar water concentration of the given $\mathrm{MeOH}$-water mixture. Three parallel measurements were carried out.

2.3. Determination of the Intrinsic Solubility by Chasing Equilibrium Solubility Method (Cheqsol). The thermodynamic solubility of the nonionized form of the samples was determined by the Chasing Equilibrium Solubility (CheqSol) method [24]. The apparatus used to perform the solubility determinations was a GLpKa titrator and a D-PAS spectrometer controlled by RefinementPro and CheqSol software (Sirius, Forest Row, UK). The titrations were performed under nitrogen atmosphere, at $0.15 \mathrm{M}$ ionic strength and $25.0 \pm 0.5^{\circ} \mathrm{C}$ using standardized $0.5 \mathrm{M} \mathrm{HCl}$ and $0.5 \mathrm{M} \mathrm{KOH}$ solutions. 
Three parallel measurements were carried out. The implementation of the experiment is described in more detail in our previous articles [19, 25].

2.4. Partition Coefficient Measurement by the Stir-Flask Method. The distribution coefficients were measured from the absorbance of the molecules before and after partitioning using standard stir-flask method as we previously reported [26].

The partition coefficient $(P)$ cannot be measured directly due to the high $\log P$ value of LAP. Therefore, the distribution coefficient $(D)$ was determined at acidic $\mathrm{pH}(\mathrm{pH}=2)$, where the molecule is in dicationic form, and at two other $\mathrm{pH}$ values at $\mathrm{pH} 5.83$ and 6.11. Three parallel measurements were carried out at each $\mathrm{pH}$. The $\mathrm{pH}$ was measured using a Metrohm 6.0204.100 combined $\mathrm{pH}$ glass electrode and a Metrohm 780 $\mathrm{pH}$ meter. The water $/ n$-octanol phase ratio varied between 250 and 600 . The $\log P$ values of each macrospecies were calculated based on the following equation:

$$
D_{\mathrm{pH}}=\chi_{i} P_{i}=\chi_{\mathrm{LAP}^{2+}} P^{\mathrm{LAP}^{2+}} * \chi_{\mathrm{LAP}^{+}} P^{\mathrm{LAP}^{+}} * \chi_{\mathrm{LAP}} P^{\mathrm{LAP}}
$$

where $\chi$ is the mole fraction of the corresponding macrospecies of the charge indicated.

2.5. Determination of Cyclodextrin Complex Stability by UV Spectroscopy. UV spectroscopic measurements were carried out on a Jasco V-550 diode-array spectrometer (Jasco, Japan) with $10 \mathrm{~mm}$ quartz cuvettes at $25^{\circ} \mathrm{C}$.

LAP was titrated with a constant amount of native CDs $(\alpha-, \beta-$, and $\gamma-\mathrm{CD})$ at $\mathrm{pH}=2$ using $0.01 \mathrm{M} \mathrm{HCl}$ as solvent. A stock solution of each CD was combined with different volumes of LAP solutions and filled to the same volume. The UV spectra were measured against a blind solution. Three parallel measurements were carried out for each CD. The complex formation equilibrium can be characterized by the following complex stability constant:

$$
K_{\text {stab }}=\frac{[\mathrm{CD}-\mathrm{LAP}]}{[\mathrm{CD}][\mathrm{LAP}]},
$$

where [CD], [LAP], and [CD-LAP] are the equilibrium concentrations of the CD, LAP, and the complex, respectively. Since the total concentrations of $\mathrm{CD}\left([\mathrm{CD}]_{T}\right)$ and LAP $\left([\mathrm{LAP}]_{T}\right)$ are known, assuming 1:1 stoichiometry, we can use the following relationships:

$$
\begin{aligned}
{[\mathrm{CD}]_{T} } & =[\mathrm{CD}]+[\mathrm{CD}-\mathrm{LAP}] \\
{[\mathrm{LAP}]_{T} } & =[\mathrm{LAP}]+[\mathrm{CD}-\mathrm{LAP}] .
\end{aligned}
$$

Since absorbance of any of the CDs is negligible and no association other than the CD-LAP formation takes place, it can be safely assumed that only LAP and the complex contribute significantly to the absorbance; therefore, the measured absorbance at any given wavelength is the weighed linear combination of the two absorbances $\left(\varepsilon_{0}\right.$ and $\varepsilon_{1}$ being the molar extinction coefficients of LAP and the complex at a given wavelength, resp.):

$$
A=\varepsilon_{0}[\mathrm{LAP}]+\varepsilon_{1}[\mathrm{CD}-\mathrm{LAP}] .
$$

Since the equilibrium concentration of LAP can be expressed in terms of the total LAP and the complex concentrations, the above equation takes on the following form:

$$
A=\varepsilon_{0}[\mathrm{LAP}]_{T}+\left(\varepsilon_{1}-\varepsilon_{0}\right)[\mathrm{CD}-\mathrm{LAP}]
$$

The complex concentration can be expressed with the stability constant $\left(K_{\text {stab }}\right)$ and the total concentrations:

$$
K_{\text {stab }}=\frac{[\mathrm{CD}-\mathrm{LAP}]}{\left([\mathrm{CD}]_{T}-[\mathrm{CD}-\mathrm{LAP}]\right)\left([\mathrm{LAP}]_{T}-[\mathrm{CD}-\mathrm{LAP}]\right)} .
$$

Solving the above quadratic equation for [CD-LAP] one can derive an equation for absorbance (using (6)), which, if fitted onto the data, provides the complex stability constant:

$$
\begin{aligned}
A= & \varepsilon_{0}[\mathrm{LAP}]_{T} \\
& +\left(\varepsilon_{1}-\varepsilon_{0}\right) \frac{\left(K_{\text {stab }}[\mathrm{CD}]_{T}+K_{\text {stab }}[\mathrm{LAP}]_{T}+1\right)-\sqrt{\left(K_{\text {stab }}[\mathrm{CD}]_{T}+K_{\text {stab }}[\mathrm{LAP}]_{T}+1\right)^{2}-4 K_{\text {stab }}^{2}[\mathrm{CD}]_{T}[\mathrm{LAP}]_{T}}}{2 K_{\text {stab }}} .
\end{aligned}
$$

Multiple fitting was performed with Opium program.

2.6. NMR Measurements. All NMR measurements were carried out on an Agilent/Varian VNMRS spectrometer $\left(600 \mathrm{MHz}\right.$ for $\left.{ }^{1} \mathrm{H}\right)$ with a $5 \mathrm{~mm}$ inverse-detection gradient probehead in $\mathrm{D}_{2} \mathrm{O} / \mathrm{DMSO}-d_{6} 7 / 3(\mathrm{v} / \mathrm{v})$ mixtures at $25^{\circ} \mathrm{C} . \mathrm{pD}^{*}$ was set to 2 using $\mathrm{DCl}$ solution. Addition of DMSO- $d_{6}$ was necessary due to the low solubility of LAP in aqueous solvents, even at acidic $\mathrm{pH}$. The chemical shifts were referenced to the solvent signal of internal DMSO. Standard pulse sequences and processing routines available in $\mathrm{VnmrJ}$ 2.2C/Chempack 4.0 were used.

For determination of complex stoichiometry, Job's continuous variation method was used. Solutions were prepared from LAP and $\beta$-CD in complementary amounts, to make up a $1.5 \mathrm{mM}$ summary concentration. The solutions were mixed in different ratios and the ${ }^{1} \mathrm{H}$ NMR spectra were recorded after $24 \mathrm{~h}$. 
The average extent of penetration and the direction of inclusion were investigated by 2D ROESY NMR. Intermolecular NOEs between LAP and CD protons directly involved in the host-guest interaction were detected as cross-peaks. In these experiments, the samples contained $1 \mathrm{mM}$ LAP and $2 \mathrm{mM} \beta$-CD. The ROESY spectrum was recorded applying a sweep width of $6 \mathrm{kHz}$ and a spinlock of $3 \mathrm{kHz}$ for a mixing time of $300 \mathrm{~ms}$. 256 increments were collected with 32 repetitions and the measured data matrix was processed as a matrix of $4 \mathrm{~K}(F 2)$ by $1 \mathrm{~K}(F 1)$ data points.

2.7. ESI-MS Experiments. High resolution accurate mass of LAP- $\beta$-CD inclusion complex was determined with an Agilent 6230 time of flight (TOF) mass spectrometer (Agilent, Germany). Samples were introduced by the Agilent 1260 Infinity LC system, and the mass spectrometer was operated in conjunction with a Jet Stream electrospray ion source in positive ion mode. Reference masses of $\mathrm{m} / z=121.050873$ and 922.009798 were used to calibrate the mass axis during analysis. The following ion source parameters were employed: flow and temperature of the drying gas: $10 \mathrm{~L} / \mathrm{min}$ and $320^{\circ} \mathrm{C}$; pressure of the nebulizer gas $\left(\mathrm{N}_{2}\right): 45$ psi; capillary voltage: $3000 \mathrm{~V}$; nozzle voltage: $500 \mathrm{~V}$; sheath gas flow and temperature: $10 \mathrm{~L} / \mathrm{min}$ and $320^{\circ} \mathrm{C}$, respectively. TOF-MS parameters were as follows: fragmentor voltage: $300 \mathrm{~V}$; skimmer potential: $170 \mathrm{~V}$; OCT $1 \mathrm{RF} V$ pp: $750 \mathrm{~V}$. $1 \mu \mathrm{L}$ of sample solution, containing $1 \mathrm{mM}$ LAP and $1 \mathrm{mM} \beta-\mathrm{CD}$, was directly injected into the mass spectrometer. Data were acquired in a 100-3000 $\mathrm{m} / \mathrm{z}$ mass range and peaks of the hypothesized complex were searched for in the $1000-3000 \mathrm{~m} / z$ interval. Mass spectra were processed by Agilent MassHunter B.04.00 software.

2.8. Phase-Solubility Studies. LAP phase-solubility studies were performed according to the method described by Higuchi and Connors [27]. Excess amount of LAP (5$6 \mathrm{mg}$ ) was added to $5 \mathrm{~mL}$ stock solution with increasing concentrations of different CDs $(\beta-\mathrm{CD}, \mathrm{HP}-\beta-\mathrm{CD}$, RAMEB, and SBE-CD) at $\mathrm{pH} 2.0$ at $0.15 \mathrm{M}$ ionic strength. The obtained suspensions were stirred for 24 hours. After sedimentation, LAP concentrations were measured from the supernatant spectrophotometrically on a Jasco V-550 instrument at $269 \mathrm{~nm}$. Three parallel measurements were carried out.

Assuming 1:1 stoichiometry, the stability constant of the complex $\left(K_{\text {stab }}\right)$ can be determined using the phase-solubility diagram according to the following equation:

$$
K_{\text {stab }}=\frac{\text { slope }}{S_{0}(1-\text { slope })}
$$

where $S_{0}$ is the intrinsic solubility of LAP in the absence of CDs.

2.9. Molecular Modeling. Molecular modeling study was performed as previously reported [19, 28, 29] by using the semiempirical PM3 method of Hyperchem Professional software (version 8.0). The initial structures of neutral LAP and $\beta$-CD were constructed with the help of Hyperchem 8.0 and optimized with PM3. A docking procedure was used to calculate the energy of the complex. LAP was moved into the CD cavity from the wider rim, step-by-step, performing a geometry optimization after each step until the conformation with the lowest energy was achieved. The docking procedure was repeated using different starting positions, and the lowest achieved energy was considered as the optimal geometry of the complex.

The stability of the complex was estimated from the formation energy:

$$
\Delta E=\text { Ecomplex }-\left(E_{\mathrm{LAP}}+E_{\mathrm{CD}}\right) .
$$

\section{Results and Discussion}

3.1. Physicochemical Characterization of LAP. Determination of the physicochemical properties of drugs is crucial to understand the pharmacokinetic behavior at the molecular level. Therefore, protonation constants, octanol/water partition coefficient, and the intrinsic solubility of LAP were determined. Due to the very low solubility of LAP, the protonation constants can only be determined by UV-pH titration with mixed-solvent procedure (Figure 2(a)). In our measurements, the $\mathrm{MeOH}$-water cosolvent system was used, where the apparent protonation constants ( $\log K^{\prime}$ values) were determined in six different mixtures; then the aqueous log $K$ s were obtained by extrapolation using Yasuda-Shedlovsky method (see (1)) taking into account the dielectric constant of the different cosolvent mixtures (Figure 2(b)). This way $\log K_{1}=$ $7.72 \pm 0.07$ and $\log K_{2}=5.08 \pm 0.05$ values were obtained.

Using the protonation constants, the distribution curves for protonation macrospecies of LAP can be depicted as a function of the $\mathrm{pH}$ (Figure 3(a)). The diagram shows that, in acidic media, at the $\mathrm{pH}$ of the stomach, the dicationic form is overwhelmingly dominant. The compound exists mainly in monocationic form at the $\mathrm{pH}$ of the blood (67.4\%). Above $\mathrm{pH} 8$, the neutral form dominates, which plays a crucial role in the transport mechanism in general, assuming that orally administrated LAP is absorbed mainly from the intestine.

Lipophilicity of LAP was characterized in terms of partition coefficient, which is the most widely used descriptor of lipophilicity in QSAR studies [30]. The working range of the used stir-flask method is -4 to +4 in $\log D$ values, limited by the accuracy of the phase volume measurement. Based on this fact, the octanol/water partition coefficient at $\mathrm{pH}$ values where the nonionized form dominates cannot be measured directly due to the very high $\log P$ value of LAP. Therefore, the $\log D$ values were measured at lower $\mathrm{pHs}$. At $\mathrm{pH} 2$, where the molecule is practically $100 \%$ dicationic, the measured $\log D_{\mathrm{pH} 2}=2.71 \pm 0.06$ characterizes the lipophilicity of the dicationic species. From $\log D$ values at $\mathrm{pH} 5.83$ (3.67 \pm 0.07$)$, $\mathrm{pH} 6.11(3.90 \pm 0.08)$, and $\mathrm{pH} 2(2.71 \pm 0.06)$, the $\log P$ value of the monocationic and neutral species could be calculated using (2). The values are summarized in Table 1 , while the $\mathrm{pH}$ dependent lipophilicity profile of LAP is in Figure 3(b).

These values indicate that LAP is an extremely lipophilic molecule and even the dicationic form has the capability to penetrate membranes by passive diffusion. These high $\log P$ values also explain the ability of LAP to cross the blood-brain barrier, which could be a further therapeutic approach in 

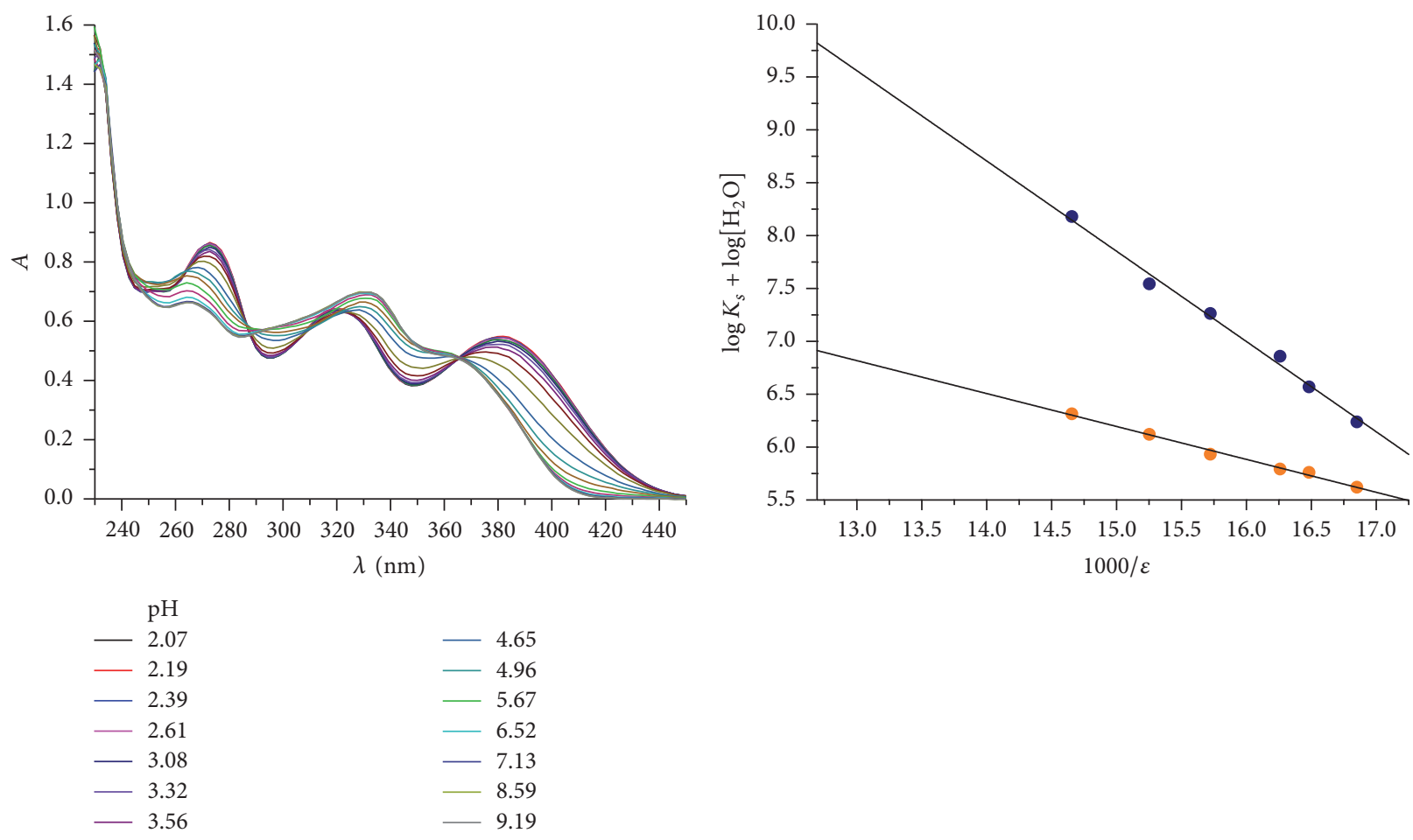

(a)

(b)

FIGURE 2: Determination of protonation constants of LAP by (a) UV/pH titration of LAP in 43/57 (w/w\%) methanol/water mixture and (b) Yasuda-Shedlovsky extrapolation.

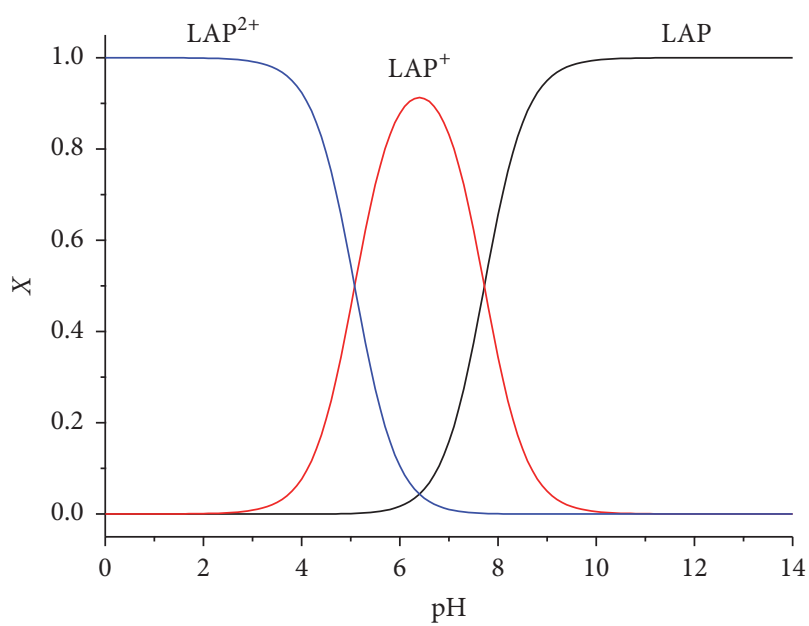

(a)

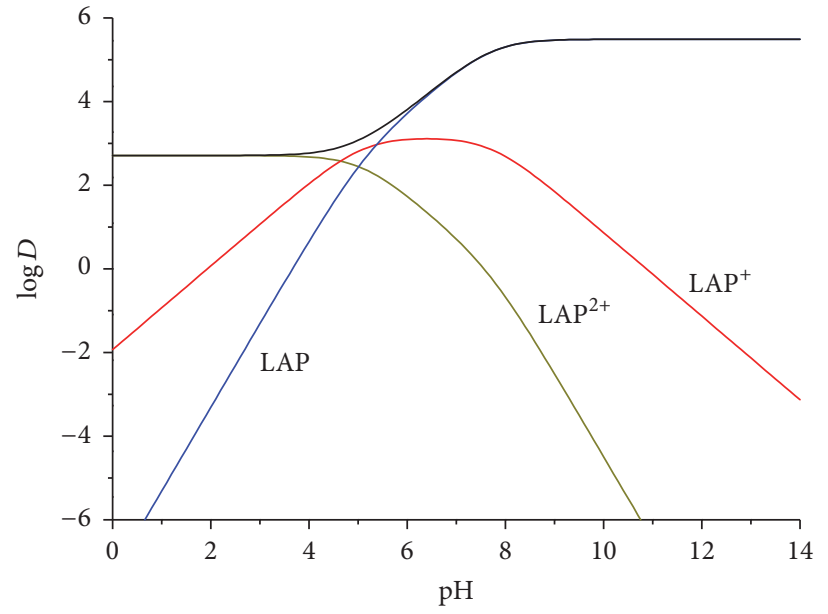

(b)

FIGURE 3: (a) Logarithmic distribution diagram for the LAP protonation macrospecies. (b) Contribution of the LAP protonation macrospecies to the lipophilicity profile (in black broad line).

brain metastasis [31]. As a part of our LAP profiling, its intrinsic solubility (the equilibrium solubility of the nonionized form) was measured by the CheqSol method, which resulted in a value of only $0.48 \mathrm{ng} / \mathrm{mL}$. LAP is a class II drug in the Biopharmaceutics Classification System, being of low water solubility and high permeability, which is in good agreement with our determined physicochemical values. These data quantify that the very poor solubility is the Achilles heel of the LAP administration. It is the root cause for the low bioavailability of the drug the necessity of taking very high doses. These problems could be alleviated by enhancing LAP solubility through CD inclusion complexation. For further pharmaceutical formulation development, optimization of CD-complex formation is crucial; therefore, interactions 


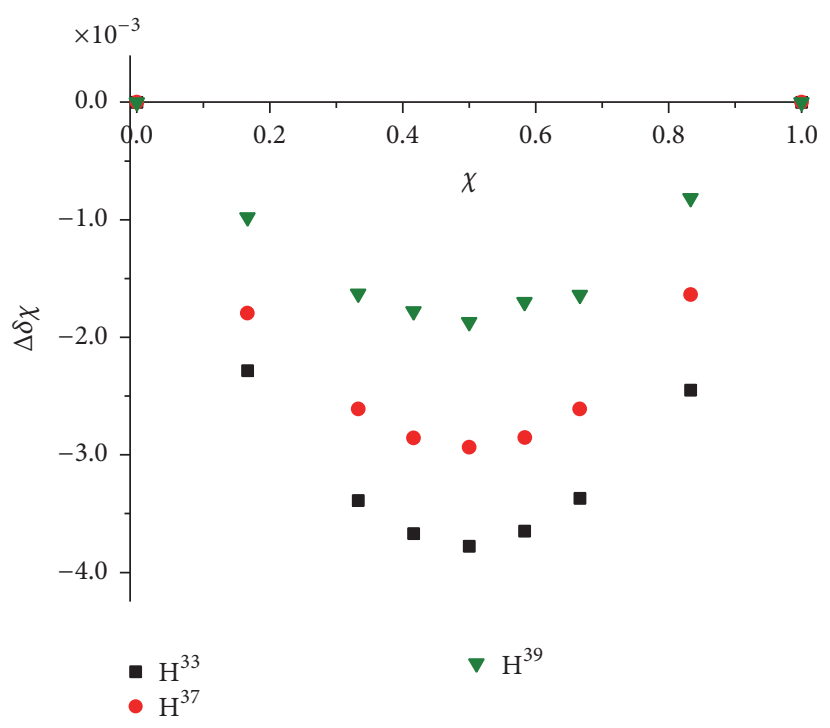

(a)

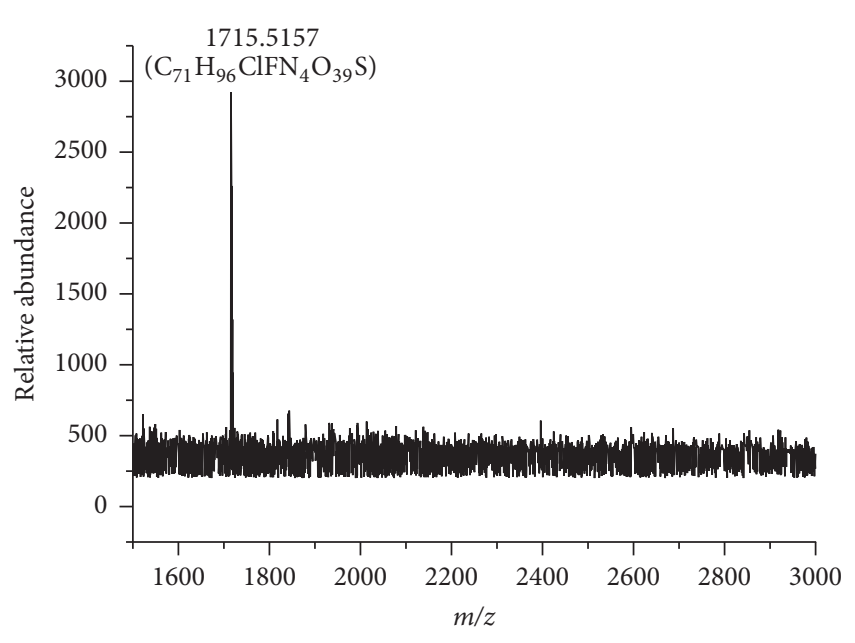

(b)

FIGURE 4: Determination of LAP- $\beta$-CD stoichiometry. (a) Representative Job plot diagrams of selected LAP protons. (b) Representative mass spectrum of a LAP- $\beta$-CD sample.

TABLE 1: Calculated $\log P$ values of the different LAP macrospecies.

\begin{tabular}{lc}
\hline Macrospecies & $\log P$ \\
\hline Dicationic & $2.71 \pm 0.07$ \\
Monocationic & $3.15 \pm 0.10$ \\
Neutral & $5.49 \pm 0.10$ \\
\hline
\end{tabular}

between LAP and CDs were characterized in solution with a wide variety of complementary analytical techniques and approaches, such as phase-solubility studies, ${ }^{1} \mathrm{H}$ and 2D NMR techniques, UV spectroscopy, and electrospray ionization-time of flight-mass spectrometry (ESI-TOF-MS).

\subsection{Determination of LAP- $\beta$-CD Stoichiometry: NMR Job Plot} and ESI-TOF-MS Studies. In order to draw adequate conclusions on the inclusion process, the knowledge of selectorselectand complexation stoichiometry is a prerequisite. The general method to determine complex stoichiometry is Job's continuous variation method. In this experiment, the ${ }^{1} \mathrm{H}$ NMR chemical shifts $(\delta)$ were measured at different LAP concentration $/ \beta-\mathrm{CD}$ concentration $\left(c_{\mathrm{LAP}} / \mathcal{c}_{\mathrm{CD}}\right)$ ratios, while the sum of $c_{\mathrm{LAP}}+c_{\mathrm{CD}}$ was kept constant. The calculated factors $\left(\Delta \delta \chi_{\text {LAP }}\right)$ were plotted as a function of LAP molar ratio $\left(\chi_{\text {LAP }}\right)$. In all cases, the resulting Job plot diagrams showed maxima at 0.5 , indicating the typical $1: 1$ binding stoichiometry. Representative Job plot curves of LAP and $\beta$ CD are shown in Figure 4(a).

The complex stoichiometry was also studied by ESI-TOFMS technique, which provides a powerful means to study noncovalent host-guest inclusion complexes between a CD and the guest molecule [32]. A large number of publications prove that a simple, fast ESI-MS analysis is suitable for the determination of inclusion complex stoichiometry [15, 19, 33]; however, ESI-MS studies imply the question whether the observed peaks represent actual inclusion complexes or rather electrostatic adducts formed during the electrospray process [34], if, however, additional adequate techniques prove that the complex formation ESI-MS is straightforward way to determine complex stoichiometry. Analyzing the MS spectra in the $100-1500 \mathrm{~m} / z$ range, the protonated molecular ion of the uncomplexed LAP $\left(m / z 581.1419[\mathrm{M}+\mathrm{H}]^{+}\right)$, their source fragment ion $\left(\mathrm{m} / z 458.1027[\mathrm{M}+\mathrm{H}]^{+}\right)$, and the characteristic $m / z$ values of uncomplexed $\beta$-CD $(m / z 1135.3732$ $\left.[\mathrm{M}+\mathrm{H}]^{+}, 1157.3531[\mathrm{M}+\mathrm{Na}]^{+}\right)$can be observed. Figure 4(b) shows the renormalized upper part $(1500-3000 \mathrm{~m} / \mathrm{z})$ of the mass spectrum of a sample containing LAP and $\beta$-CD in $1: 2$ molar ratio. The observed signal at $m / z 1715.5157$ with generated $\mathrm{C}_{71} \mathrm{H}_{96} \mathrm{ClFN}_{4} \mathrm{O}_{39} \mathrm{~S}$ molecular formula corresponds to the LAP- $\beta$-CD $1: 1$ inclusion complex, which means that ESITOF-MS confirms the NMR Job result, verifying the $1: 1$ stoichiometry.

3.3. Determination of Stability Constant by UV. UV spectroscopy can be a sensitive technique to characterize the CD inclusion complexes, provided that the guest molecule undergoes the significant absorption changes upon complexation. This technique can be used for the determination of CD stability constant of molecules with low solubility as well. Using (8), the stability constants between LAP and native CDs were determined to select the most suitable host. The stability constants determined at $\mathrm{pH} 2$ are listed in Table 2.

Based on these data, we can conclude that, concerning the size, the seven-membered $\beta$-CD is the most suitable host molecule for complexation. Thus, further experiments were carried out with $\beta$-CD and its derivatives.

3.4. Structure of the LAP- $\beta$-CD Complex. 2D ROESY NMR combined with molecular modeling is an appropriate way 


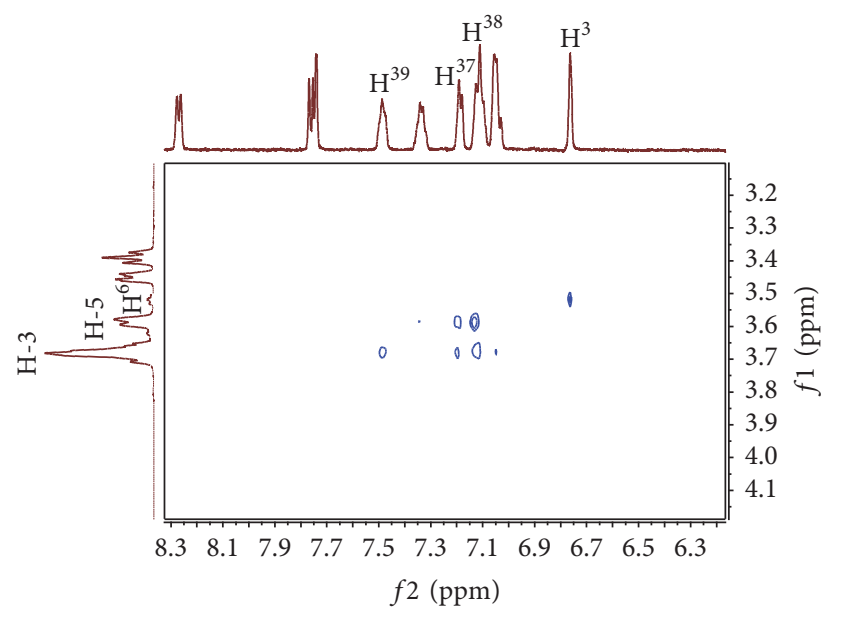

(a)

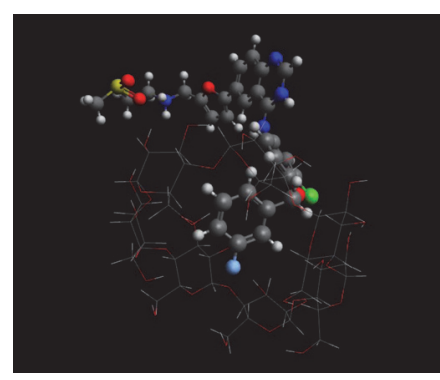

(b)

FIGURE 5: Determination of the LAP- $\beta$-CD inclusion complex geometry. (a) Expansion of 2D ROESY NMR spectrum. (b) Energy-minimized structure of the complex based on the result of molecular modeling study.

TABLE 2: Determined $K_{\text {stab }}$ values at $\mathrm{pH} 2$ for different LAP-CD complexes with UV spectroscopy.

\begin{tabular}{lc}
\hline $\mathrm{CD}$ & $K_{\text {stab }}\left(\mathrm{M}^{-1}\right)$ \\
\hline$\alpha-\mathrm{CD}$ & $46 \pm 8$ \\
$\beta-\mathrm{CD}$ & $121 \pm 12$ \\
$\gamma$-CD & $89 \pm 6$ \\
\hline
\end{tabular}

to characterize the geometry of inclusion complexes. ROESY experiment offers valuable information on spatial proximity between protons of the host and guest molecules by observing intermolecular dipolar cross-correlations, while molecular modeling seeks the energy-minimized structure, which can be visualized at the atomic level $[19,35,36]$.

2D NMR ROESY spectra for LAP- $\beta$-CD inclusion complex were recorded at $\mathrm{pD}^{*} 2$, where LAP exhibits an appropriate solubility. The expansion of this $2 \mathrm{D}$ spectrum in Figure 5(a) contains an intramolecular cross-peak between $\mathrm{H}^{3}$ (6.76 ppm) and $\mathrm{H}^{6}$ (3.52 ppm) nuclei of LAP. From the viewpoint of encapsulation intermolecular cross-peaks of the fluorophenyl protons $\left(\mathrm{H}^{37,38,39}\right)$ with the inner $\mathrm{H}-3$ (3.68 ppm) and $\mathrm{H}-5$ (3.58 $\mathrm{ppm}$ ) protons of $\beta-\mathrm{CD}$ are crucial. Due to the fact that the $\mathrm{H}^{39}(7.49 \mathrm{ppm})$ proton of LAP gives a stronger cross-peak with the $\mathrm{H}-3$ proton of the $\mathrm{CD}$, we can assume that the fluorophenyl moiety is accommodated in the $\mathrm{CD}$ cavity from the wider rim. Based on ROESY data, molecular modeling at PM3 level was carried out. The energyminimization structure is depicted in Figure 5(b). The energy of formation of the complex was found $-10.7 \mathrm{kcal} / \mathrm{mol}$, indicating that complex formation is thermodynamically favored.

3.5. Phase-Solubility Studies. Phase-solubility analysis according to Higuchi and Connors is an appropriate technique to demonstrate changes in drug solubility. Moreover, stability constants and stoichiometry can also be determined [9]. Upon addition of increasing amounts of CDs $(\beta-C D$,
TABLE 3: $K_{\text {stab }}$ values calculated from phase-solubility studies for the CDs employed.

\begin{tabular}{lc}
\hline CD & $K_{\text {stab }}\left(\mathrm{M}^{-1}\right)$ \\
\hline$\beta$-CD & $131 \pm 9$ \\
RAMEB & $331 \pm 15$ \\
HP- $\beta$-CD & $537 \pm 20$ \\
SBE-CD & $31622 \pm 120$ \\
\hline
\end{tabular}

RAMEB, HP- $\beta$-CD, and SBE-CD) at $\mathrm{pH} 2$, linear solubility enhancement was observed for LAP, regardless of the $\mathrm{CD}$ employed (Figure 6).

The resulting $\mathrm{A}_{\mathrm{L}}$-type linear positive isotherms reveal 1:1 binding stoichiometry, further supporting Job plot and ESI-TOF-MS results. The $K_{\text {stab }}$ values calculated by (9) are summarized in Table 3.

The determined $K_{\text {stab }}$ value for $\beta$-CD by UV spectroscopy and phase-solubility is in agreement. Moreover similar stability constants were determined for other cyclodextrin complexes of tyrosine kinase inhibitors $[15,16,19]$. The values in Table 3 show that the substitution of the $\beta$-CD enhances inclusion complex formation stability as observed also in the case of erlotinib [19]. However, in the case of imatinib, the methylation of the native $\beta$-CD reduced the stability of the complex [15], which can be explained by the structural differences of these anticancer drugs. The largest binding constant was observed for SBE- $\beta$-CD, which is totally ionized under the applied conditions. Thus, the reason of the more stable complex is the additional electrostatic attractions between the multiply negatively charged hosts and the dicationic LAP. Concerning the solubility enhancing capabilities, it can be stated that $\mathrm{CD}$ derivatives enhance the LAP solubility due primarily to the inclusion phenomenon, which can be extended by electrostatic forces. The results are especially promising with SBE- $\beta$-CD where more than 600 -fold solubility increase could be achieved. 


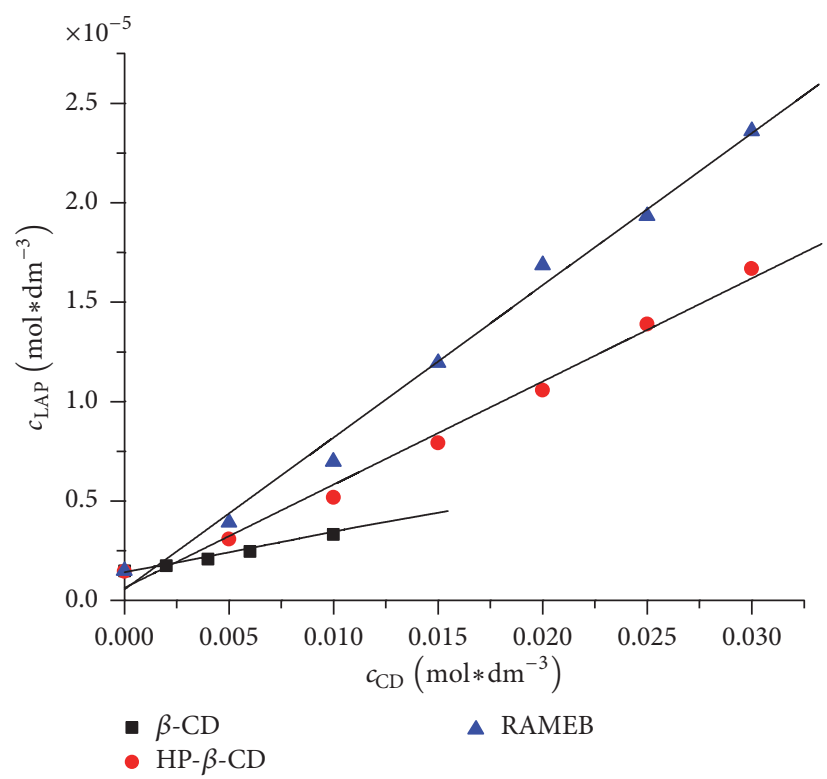

(a)

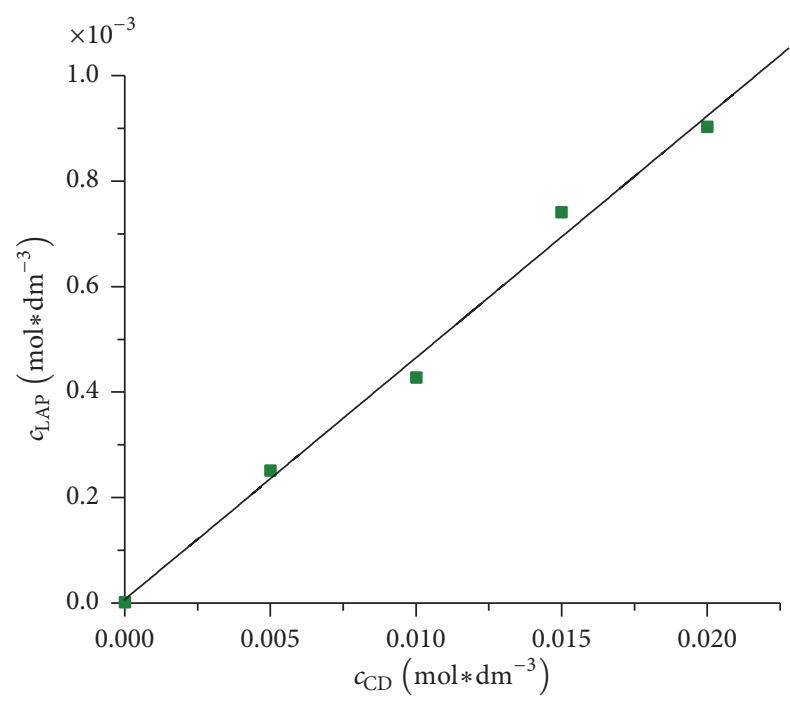

- SBE-CD

FIGURE 6: Phase-solubility diagrams of LAP-CD complexes.

\section{Conclusion}

LAP, the anticancer drug, was characterized in terms of lipophilicity, solubility, acid-base, and CD-complex formation properties, using complementary methods, such as UV, NMR, phase-solubility, and molecular modeling. An important practical result of this work is that CDs, especially the substituted derivatives, significantly increase the LAP solubility, which can be a starting point of a new LAP formulation of improved bioavailability.

\section{Competing Interests}

The authors declare no conflict of interests.

\section{Authors' Contributions}

Gergő Tóth and Ádám Jánoska contributed equally to this work.

\section{Acknowledgments}

The research was supported through the New National Excellence Program of the Ministry of Human Capacities (Ádám Jánoska).

\section{References}

[1] G. M. Higa and J. Abraham, "Lapatinib in the treatment of breast cancer," Expert Review of Anticancer Therapy, vol. 7, no. 9, pp. 1183-1192, 2007.

[2] C. E. Geyer, J. Forster, D. Lindquist et al., "Lapatinib plus capecitabine for HER2-positive advanced breast cancer," New
England Journal of Medicine, vol. 355, no. 26, pp. 2733-2743, 2006.

[3] S. Johnston, J. Pippen Jr., X. Pivot et al., "Lapatinib combined with letrozole versus letrozole and placebo as first-line therapy for postmenopausal hormone receptor-positive metastatic breast cancer," Journal of Clinical Oncology, vol. 27, no. 33, pp. 5538-5546, 2009.

[4] H. A. Burris III, C. W. Taylor, S. F. Jones et al., "A phase I and pharmacokinetic study of oral lapatinib administered once or twice daily in patients with solid malignancies," Clinical Cancer Research, vol. 15, no. 21, pp. 6702-6708, 2009.

[5] L. A. Devriese, K. M. Koch, M. Mergui-Roelvink et al., "Effects of low-fat and high-fat meals on steady-state pharmacokinetics of lapatinib in patients with advanced solid tumours," Investigational New Drugs, vol. 32, no. 3, pp. 481-488, 2014.

[6] K. M. Koch, Y.-H. Im, S.-B. Kim et al., "Effects of esomeprazole on the pharmacokinetics of lapatinib in breast cancer patients," Clinical Pharmacology in Drug Development, vol. 2, no. 4, pp. 336-341, 2013.

[7] C. Leuner, "Improving drug solubility for oral delivery using solid dispersions," European Journal of Pharmaceutics and Biopharmaceutics, vol. 50, no. 1, pp. 47-60, 2000.

[8] R. L. Carrier, L. A. Miller, and I. Ahmed, "The utility of cyclodextrins for enhancing oral bioavailability," Journal of Controlled Release, vol. 123, no. 2, pp. 78-99, 2007.

[9] K. A. Connors, "The stability of cyclodextrin complexes in solution," Chemical Reviews, vol. 97, no. 5, pp. 1325-1358, 1997.

[10] J. Szejtli, "Introduction and general overview of cyclodextrin chemistry," Chemical Reviews, vol. 98, no. 5, pp. 1743-1753, 1998.

[11] T. Loftsson and D. Duchene, "Cyclodextrins and their pharmaceutical applications," International Journal of Pharmaceutics, vol. 329, no. 1-2, pp. 1-11, 2007.

[12] H. Gao, Y. Wang, C. Chen et al., "Incorporation of lapatinib into core-shell nanoparticles improves both the solubility and antiglioma effects of the drug," International Journal of Pharmaceutics, vol. 461, no. 1-2, pp. 478-488, 2014. 
[13] L. Zhang, S. Zhang, S.-B. Ruan, Q.-Y. Zhang, Q. He, and H.L. Gao, "Lapatinib-incorporated lipoprotein-like nanoparticles: preparation and a proposed breast cancer-targeting mechanism," Acta Pharmacologica Sinica, vol. 35, no. 6, pp. 846-852, 2014.

[14] Y. Song, X. Yang, X. Chen, H. Nie, S. Byrn, and J. W. Lubach, "Investigation of drug-excipient interactions in lapatinib amorphous solid dispersions using solid-state NMR spectroscopy," Molecular Pharmaceutics, vol. 12, no. 3, pp. 857-866, 2015.

[15] S. Béni, Z. Szakács, O. Csernák, L. Barcza, and B. Noszál, “Cyclodextrin/imatinib complexation: binding mode and charge dependent stabilities," European Journal of Pharmaceutical Sciences, vol. 30, no. 2, pp. 167-174, 2007.

[16] Y.-H. Phillip Lee, S. Sathigari, Y.-J. Jean Lin et al., "Gefitinibcyclodextrin inclusion complexes: physico-chemical characterization and dissolution studies," Drug Development and Industrial Pharmacy, vol. 35, no. 9, pp. 1113-1120, 2009.

[17] N. Devasari, C. P. Dora, C. Singh et al., "Inclusion complex of erlotinib with sulfobutyl ether- $\beta$-cyclodextrin: preparation, characterization, in silico, in vitro and in vivo evaluation," Carbohydrate Polymers, vol. 134, pp. 547-556, 2015.

[18] S. M. L. Gontijo, P. P. G. Guimarães, C. T. R. Viana et al., "Erlotinib/hydroxypropyl- $\beta$-cyclodextrin inclusion complex: characterization and in vitro and in vivo evaluation," Journal of Inclusion Phenomena and Macrocyclic Chemistry, vol. 83, no. 34, pp. 267-279, 2015.

[19] G. Tóth, Á. Jánoska, Z.-I. Szabó et al., "Physicochemical characterisation and cyclodextrin complexation of erlotinib," Supramolecular Chemistry, vol. 28, no. 7-8, pp. 656-664, 2016.

[20] D. W. Rusnak, K. Lackey, K. Affleck et al., "The effects of the novel, reversible epidermal growth factor receptor/ErbB-2 tyrosine kinase inhibitor, GW2016, on the growth of human normal and tumor-derived cell lines in vitro and in vivo," Molecular Cancer Therapeutics, vol. 1, no. 2, pp. 85-94, 2001.

[21] M. J. Sambade, R. J. Kimple, J. T. Camp et al., "Lapatinib in combination with radiation diminishes tumor regrowth in HER2+ and basal-like/EGFR+ breast tumor xenografts," International Journal of Radiation Oncology, Biology, Physics, vol. 77, no. 2, pp. 575-581, 2010.

[22] K. Y. Tam and K. Takács-Novák, "Multi-wavelength spectrophotometric determination of acid dissociation constants: a validation study," Analytica Chimica Acta, vol. 434, no. 1, pp. 157-167, 2001.

[23] G. Völgyi, R. Ruiz, K. Box, J. Comer, E. Bosch, and K. Takács-Novák, "Potentiometric and spectrophotometric pKa determination of water-insoluble compounds: validation study in a new cosolvent system," Analytica Chimica Acta, vol. 583, no. 2, pp. 418-428, 2007.

[24] M. Stuart and K. Box, "Chasing equilibrium: measuring the intrinsic solubility of weak acids and bases," Analytical Chemistry, vol. 77, no. 4, pp. 983-990, 2005.

[25] G. Völgyi, E. Baka, K. J. Box, J. E. A. Comer, and K. Takács-Novák, "Study of pH-dependent solubility of organic bases. Revisit of Henderson-Hasselbalch relationship," Analytica Chimica Acta, vol. 673, no. 1, pp. 40-46, 2010.

[26] G. Tóth, K. Mazák, S. Hosztafi, J. Kökösi, and B. Noszál, "Species-specific lipophilicity of thyroid hormones and their precursors in view of their membrane transport properties," Journal of Pharmaceutical and Biomedical Analysis, vol. 76, pp. 112-118, 2013.

[27] T. Higuchi and K. A. Connors, "Phase solubility studies," in Advances in Analytical Chemistry and Instrumentation, C. N.
Reilly, Ed., pp. 117-212, Wiley-Interscience, New York, NY, USA, 1965.

[28] K. M. Al Azzam and E. Muhammad, "Host-guest inclusion complexes between mitiglinide and the naturally occurring cyclodextrins $\alpha, \beta$, and $\gamma$ : a theoretical approach," Advanced Pharmaceutical Bulletin, vol. 5, no. 2, pp. 289-291, 2015.

[29] X. Wen, F. Tan, Z. Jing, and Z. Liu, "Preparation and study the 1:2 inclusion complex of carvedilol with $\beta$-cyclodextrin," Journal of Pharmaceutical and Biomedical Analysis, vol. 34, no. 3, pp. 517523, 2004.

[30] C. Hansch, "On the future of QSAR," in Medicinal Chemistry for the 21st Century, C. G. Wermuth, N. Koga, and H. König, Eds., pp. 281-293, Metcalf Blackwell, Oxford, UK, 1994.

[31] A. Morikawa, D. M. Peereboom, Q. R. Smith et al., "Clinical evidence for drug penetration of capecitabine and lapatinib uptake in resected brain metastases from women with metastatic breast cancer," Journal of Clinical Oncology, vol. 31, no. 15, supplement 1 , abstract 514, 2013, Proceedings of the 2013 ASCO Annual Meeting.

[32] Y. Dotsikas and Y. L. Loukas, "Efficient determination and evaluation of model cyclodextrin complex binding constants by electrospray mass spectrometry," Journal of the American Society for Mass Spectrometry, vol. 14, no. 10, pp. 1123-1129, 2003.

[33] N. Marangoci, M. Mares, M. Silion et al., "Inclusion complex of a new propiconazole derivative with $\beta$-cyclodextrin: NMR, ESI-MS and preliminary pharmacological studies," Results in Pharma Sciences, vol. 1, no. 1, pp. 27-37, 2011.

[34] J. B. Cunniff and P. Vouros, "False positives and the detection of cyclodextrin inclusion complexes by electrospray mass spectrometry," Journal of the American Society for Mass Spectrometry, vol. 6, no. 5, pp. 437-447, 1995.

[35] D. Salvatierra, C. Jaime, A. Virgili, and F. Sánchez-Ferrando, "Determination of the inclusion geometry for the $\beta$-cyclodextrin/benzoic acid complex by NMR and molecular modeling," Journal of Organic Chemistry, vol. 61, no. 26, pp. 9578-9581, 1996.

[36] Z.-I. Szabó, F. Mohammadhassan, L. Szőcs et al., "Stereoselective interactions and liquid chromatographic enantioseparation of thalidomide on cyclodextrin-bonded stationary phases," Journal of Inclusion Phenomena and Macrocyclic Chemistry, vol. 85 , no. 3-4, pp. 227-236, 2016. 

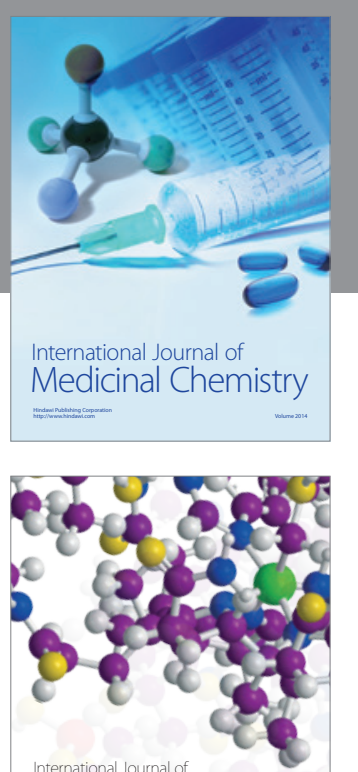

Carbohydrate Chemistry

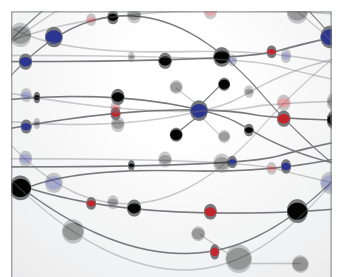

The Scientific World Journal
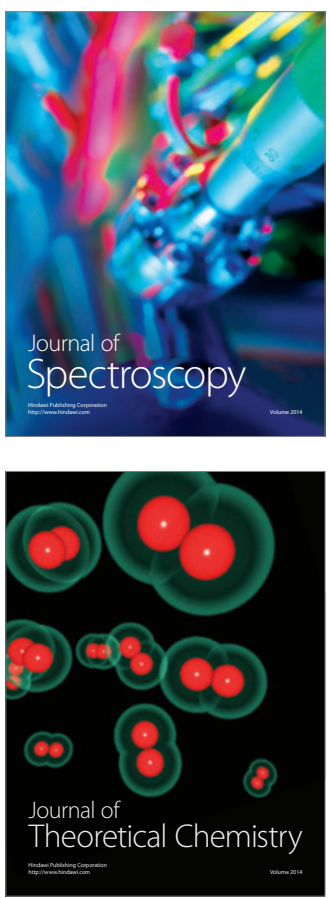
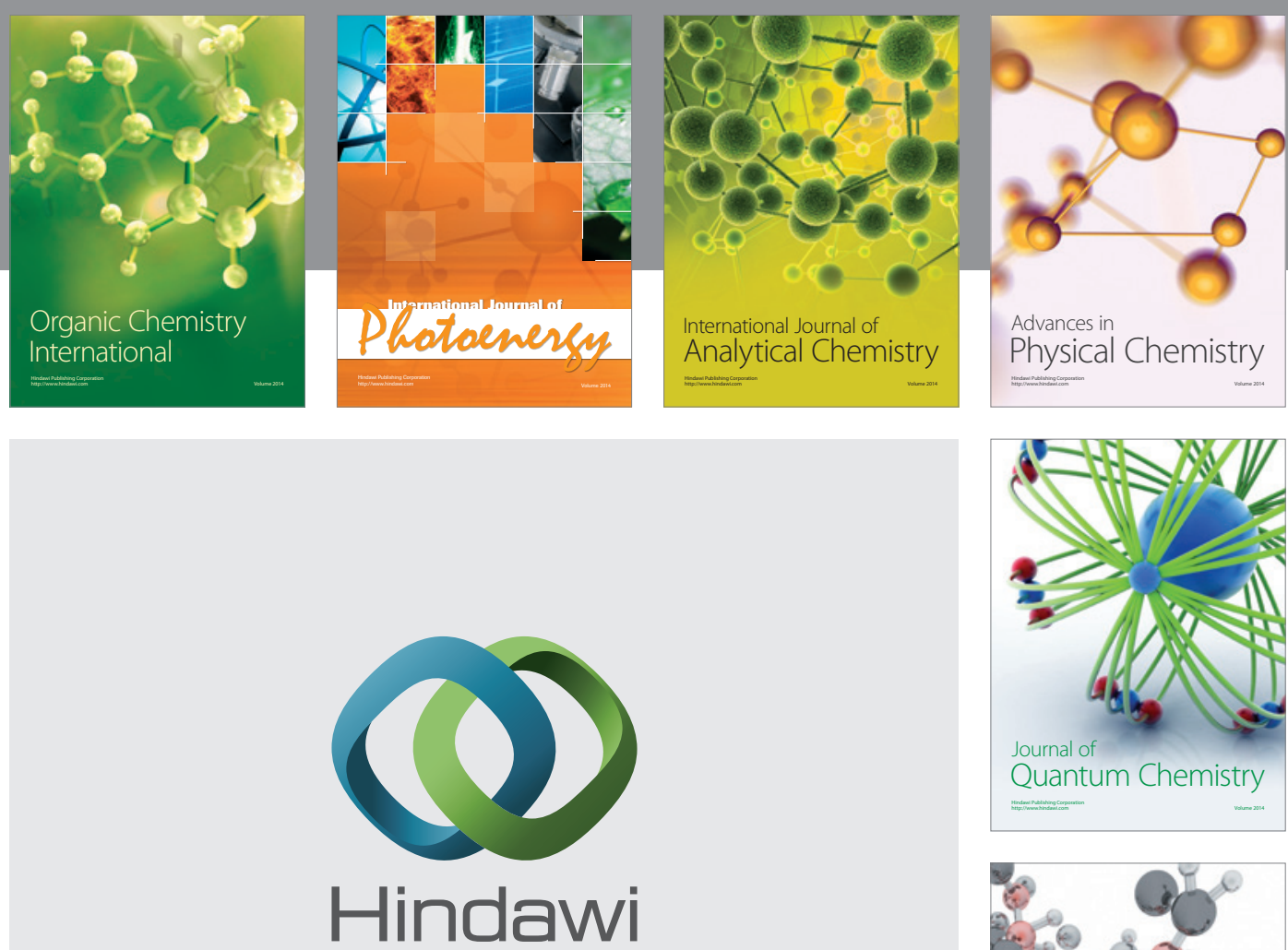

Submit your manuscripts at

https://www.hindawi.com

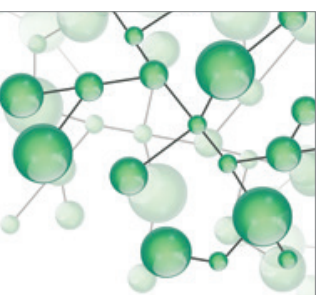

International Journal of

Inorganic Chemistry
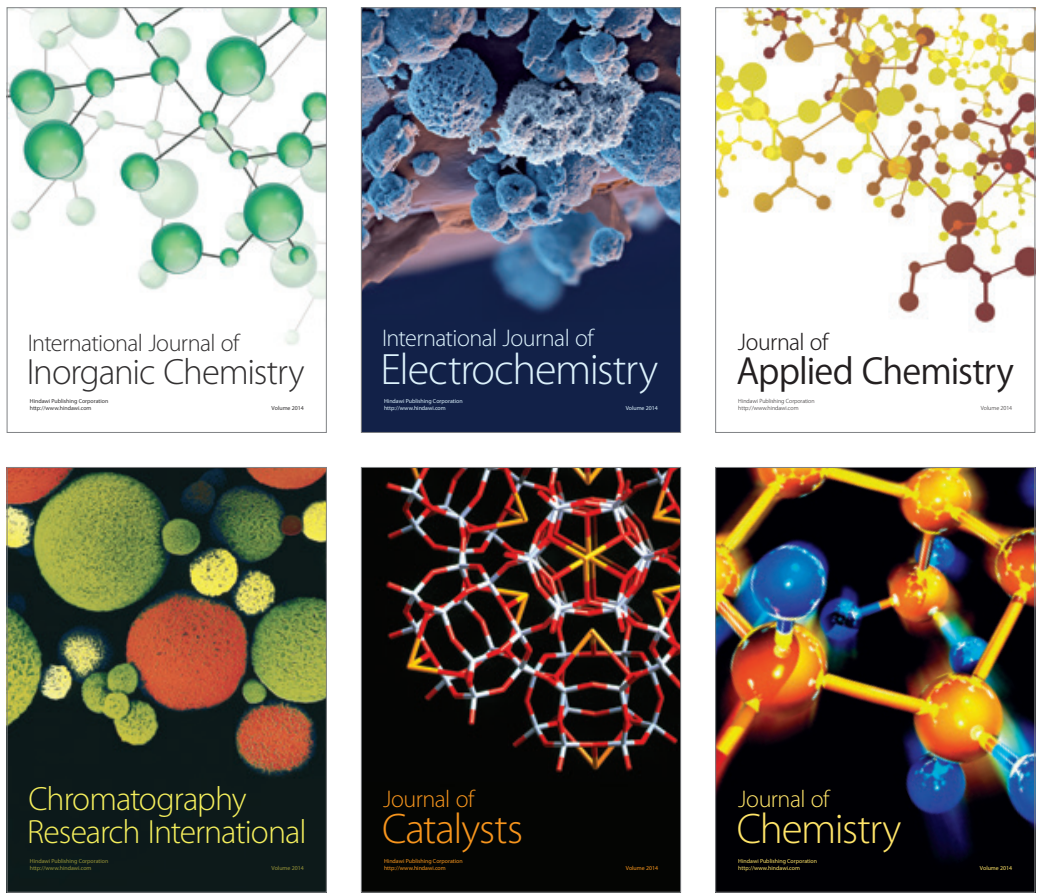

Journal of

Applied Chemistry
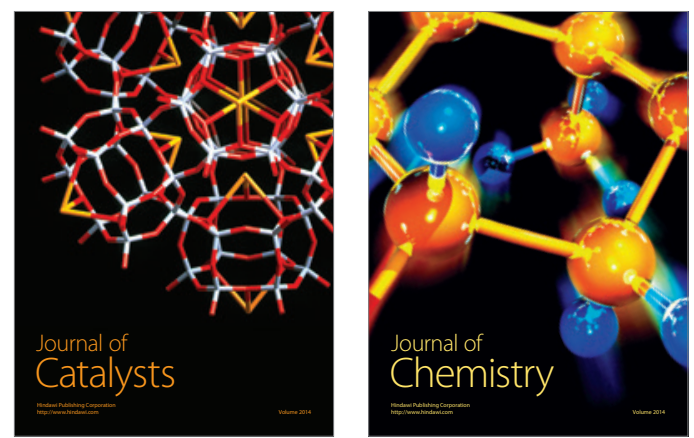
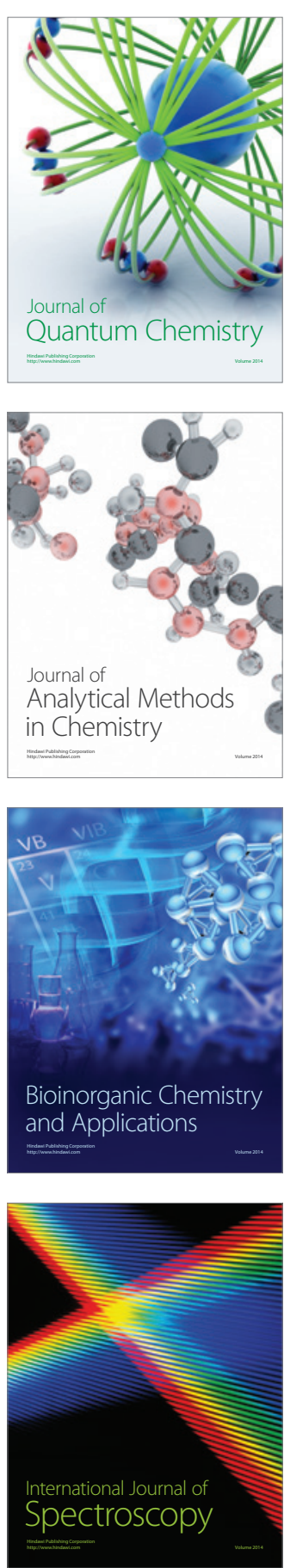